\title{
Seismic Performance of Existing RC Structural Walls Retrofitted in Flexure by Wall End Plate
}

\author{
Su-Yong Kim ${ }^{1}$, Uijin Cho ${ }^{1}{ }^{\circledR}$, Joo-Hong Chung ${ }^{2}$, Baek-Il Bae ${ }^{3}$ and Chang-Sik Choi ${ }^{1, *}$ \\ 1 Department of Architectural Engineering, Hanyang University, Seoul 04763, Korea; \\ suyonggo@naver.com (S.-Y.K.); creedjay@hanyang.ac.kr (U.C.) \\ 2 Department of Architecture, Sahmyook University, Seoul 01795, Korea; scarletmoon@syu.ac.kr \\ 3 Department of Digital Architecture and Urban Engineering, Hanyang Cyber University, Seoul 04763, Korea; \\ bibae@hycu.ac.kr \\ * Correspondence: ccs5530@hanyang.ac.kr
}

Citation: Kim, S.-Y.; Cho, U.; Chung, J.-H.; Bae, B.-I.; Choi, C.-S. Seismic Performance of Existing RC Structural Walls Retrofitted in Flexure by Wall End Plate. Sustainability 2021, 13, 509. https://doi.org/10.3390/ su13020509

Received: 9 November 2020 Accepted: 6 January 2021 Published: 7 January 2021

Publisher's Note: MDPI stays neutral with regard to jurisdictional clai$\mathrm{ms}$ in published maps and institutional affiliations.

Copyright: ( 2021 by the authors. Licensee MDPI, Basel, Switzerland. This article is an open access article distributed under the terms and conditions of the Creative Commons Attribution (CC BY) license (https:// creativecommons.org/licenses/by/ $4.0 /)$.

\begin{abstract}
A study was conducted for the flexural retrofit of an old apartment house composed of a reinforced concrete (RC) shear wall structure. For the shear wall, a vertical retrofit was performed to both ends of the wall targeting the slender wall to improve the flexural performance. The retrofit materials were steel plate, epoxy, and non-shrink grout, and they were connected to the existing shear wall using post-installed chemical anchors. The concrete at the wall ends was broken and retrofitted as much as necessary to maintain the shear wall's length. The points to be noted are the fracture of the welded part of the flexural retrofit and the chemical anchor's pulling. After the real scale specimen was fabricated by simulating the existing shear wall, the retrofit effect was experimentally verified by breaking the wall ends, retrofitting the ends, and applying repeated cyclic lateral loads. A total of three specimens were fabricated and retrofitted using steel plates and steel tubes. Since this experiment evaluated the flexural performance, the experiment was performed with a cantilever setting. The flexural retrofit effect using steel was analyzed through the load-displacement relationship, stiffness degradation, and energy dissipation, and through this, the bond of the retrofit and the behavior of the wall were verified.
\end{abstract}

Keywords: reinforced concrete; wall retrofit; flexural retrofit; boundary element; rehabilitation

\section{Introduction}

As reinforced concrete $(\mathrm{RC})$ buildings age, the structure's reliability decreases when external forces such as seismic or wind load are applied. Besides, when an old facility's maintenance or remodeling is performed, the existing RC structure must be retrofitted to compensate for an increase in load that was not considered during design. The retrofit method used in existing RC structures is a form of attaching steel or fiber-reinforced polymer (FRP) materials to structural members. However, the RC shear wall structural system is more delicate to dimensional changes than the beam-column frame system because each shear wall is used not only as a load-bearing wall but also as a partition wall for planning, and when the dimensions change, it causes a decrease in the interior area or a change of movement lines of residents.

Shear wall retrofit is classified into shear and flexural retrofit. Most previous studies and retrofit methods target shear retrofit, and studies on flexural retrofit are still in progress. Therefore, this study aimed to develop a flexural retrofit method of an existing shear wall and limited rectangular shear walls. The flexural retrofit is divided into a method through selective weakening with post-tensioning [1-5] and attaching a retrofit material. In the case of selective weakening with post-tensioning, the shear wall of the part where the bending stress to be concentrated is cut to disperse the stress. The strength decreases due to cross-sectional loss but is increased through post-tensioning by applying axial load. Methods of attaching the retrofit material include the externally bonded retrofit method 
(EBR) [6-12], which attaches the retrofit to the wall, and the near-surface mounted method (NSM) using concrete cover [13-21]. It is a method to improve the strength against bending by attaching high-performance materials compared to concrete to improve cross-sectional performance.

Both methods can effectively improve the shear wall's flexural strength, but various disadvantages are problematic and have not been solved yet. First, selective weakening has a sense of resistance to cross-sectional loss, which is a method contrary to retrofit, and it is difficult to secure an anchorage for post-tensioning, and the tendon must be exposed outside the wall. Additionally, since the axial load applied to the wall increases, there may be a problem that the time at which concrete crushing occurs is accelerated under a high lateral load. In the case of EBR, there may be problems that the stress is concentrated in the part that is not bonded or the retrofit material peels off, and the cracks occurring in the existing shear wall cannot be observed, and the interior area decreases by the thickness of the retrofit material. In the NSM retrofit method, since the retrofit material is embedded in the concrete cover, the shear wall's dimensions do not change, but the retrofit material's peeling and development method have not been resolved.

The concept reviewed to solve these problems is the details of the reinforcement of the new shear wall. Although the names and the details are different according to the seismic codes, well-confined boundary elements are specified at both ends of the shear wall to effectively bear the lateral load and improve flexural strength and ductility [22-29]. When the RC shear wall's behavior is subjected to a lateral load such as a seismic load, a large compressive force is generated at the wall end, which affects the structure's safety. Therefore, the boundary element located at the wall end performs an essential role in improving the entire structure's performance. The shear wall of the building targeted in this study is at least 15 years old, and longitudinal rebars are evenly arranged throughout the shear wall cross-section. When a high lateral load is applied to a wall dominated by flexure, the problem occurs at both ends where the highest bending stress occurs, thus it effectively concentrates longitudinal and transverse rebars in this area.

Based on this concept, Cho et al. [30], a previous study of this study, developed a retrofit method by excavating to create boundary elements using reinforcement and concrete on the existing RC shear wall. In order to increase the flexural strength up to that required, the amount of reinforcement was calculated through the ultimate strength design method, and then the ends of the shear wall were broken to the required length for reinforcement arrangement. Besides, while breaking the end of the shear wall, the transverse rebar of the existing shear wall was preserved about $100 \mathrm{~mm}$ or more to connect the existing shear wall and the newly constructed boundary element. For this reason, the retrofit method was named the excavating retrofit method. Longitudinal rebars for retrofit were attached to the existing structural members using the epoxy for post-installed chemical anchors, and the transverse rebars were connected to the preserved transverse rebars by welding. As the expected retrofit effect was obtained by establishing boundary elements using rebar and concrete, a study was conducted to supplement this. Since concrete is a wet material, the construction period and process increase for formwork installation, concrete placement, and curing, thus a retrofit method using steel, a dry material, was devised. It was also expected that the length of breaking at the end of the shear wall end of at least $300 \mathrm{~mm}$ or more to secure the rebar spacing could be reduced using steel.

\section{Flexural Retrofit Methods for RC Shear Wall}

\subsection{Necessity of Shear Wall Flexural Retrofit}

Shear wall structural systems are limited in plan change. Additionally, residential buildings that have passed about 15 years after construction need maintenance, and one of the methods is an extension. Extensions are classified into vertical and horizontal extensions. In this case, a new floor can be created on the top, or a new plan can be obtained horizontally through extension while maintaining the existing building's plan. 
For example, in Korea, the Housing Act has been established to allow vertical extension of three floors for apartment houses with 15 floors or more. In this case, since the height and the self-weight of the existing building increase, a structural retrofit may occur in some shear walls, and the flexural strength within about 50\% compared to the existing strength needs to be increased [31]. Figure 1 shows the retrofit necessity according to the increase in load applied to the shear wall structure.

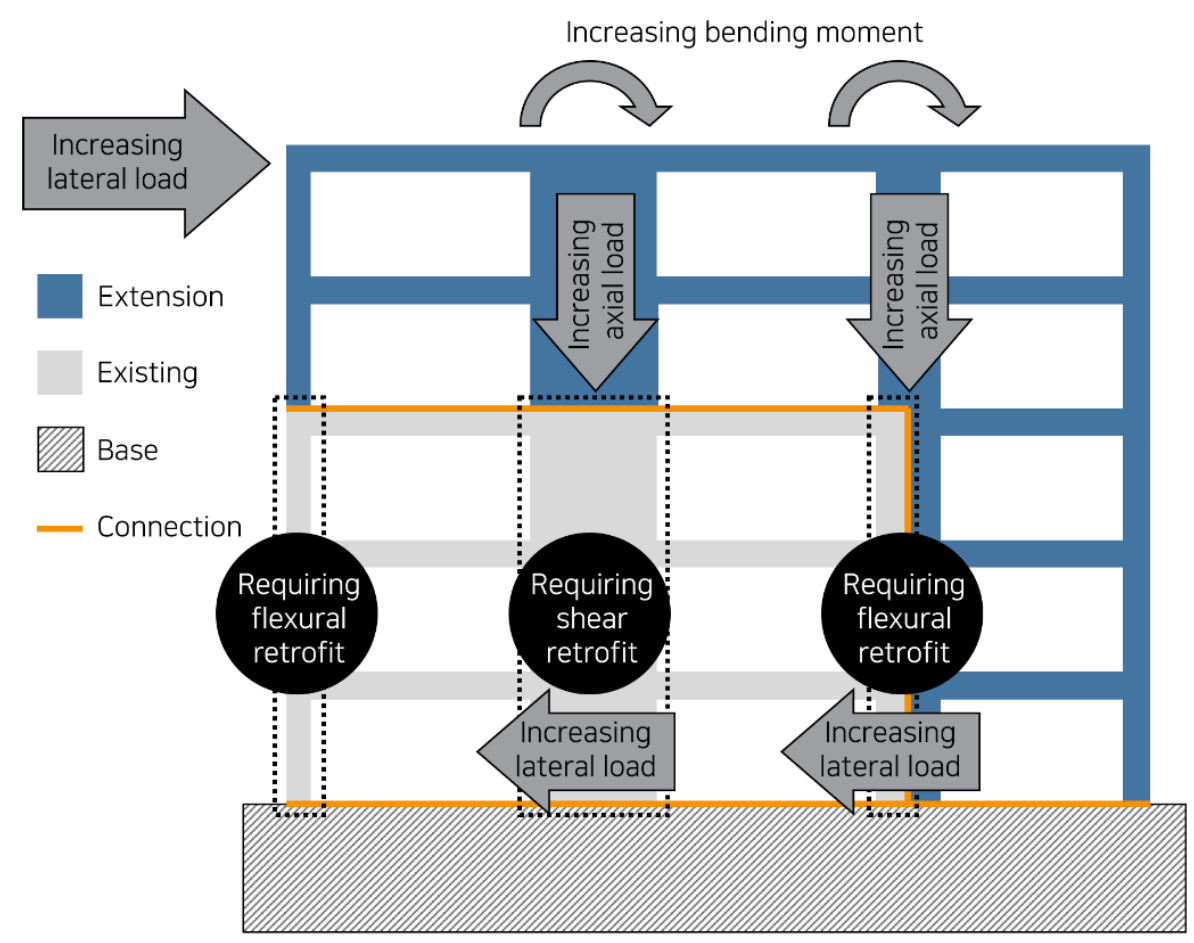

Figure 1. Requirement of shear wall retrofit [31].

\subsection{Flexural Retrofit Method Using Steel}

\subsubsection{Retrofit Strategy}

The retrofit material used in the flexural retrofit method using steel is a steel plate and a rectangular steel tube made by welding steel plates. Each of the two materials has a different purpose of use and a different construction procedure. Table 1 shows the difference between the retrofit method using a steel plate and tube. The difference is that the steel plate is attached to the wall as with EBR but is attached in the thickness direction rather than the wall's length direction. In order to maintain the length of the wall, the steel plate is attached after chipping the concrete cover thickness. Therefore, it is possible to minimize the use of retrofit materials while maximizing the effect of flexural retrofit and maintaining the longitudinal rebars located at the end of the existing shear wall. It is an easy method for a shear wall that is difficult to break the wall end or a wall tensioned by an overturning moment.

Table 1. Differences in flexural retrofit using steel plate and steel tube.

\begin{tabular}{ccc}
\hline Differences & Steel Plate & Steel Tube \\
\hline Concrete breaking length & Concrete cover thickness & Steel tube's size \\
Existing longitudinal rebars at wall end & Preserved & Cut \\
Construction difficulty & Low & High \\
Buckling resistance & Low & High \\
\hline
\end{tabular}

On the other hand, the steel tube filling the non-shrink grout inside can perform effectively on the compression force and the tensile force because the rectangular steel 
tube plays the formwork and the transverse rebar. When the grout filled in the inside is subjected to compression force, the confinement effect is shown by the rectangular steel tube, and higher compression performance can be expressed. This is the same concept as attaching a slender concrete-filled tube (CFT) column to the wall ends. It is known to show high flexural performance when retrofitting a circular steel tube by embedding it into the precast concrete wall's end [32-34], but problems such as development and peeling that occur in the retrofitting process of the existing shear wall cannot be considered. These attempts also relieve the reinforcement details of the new shear wall's boundary elements, not the concept of retrofit to the existing wall.

Non-shrink grout is a wet material; it has the advantage that it does not require formwork and is easier to cure than the excavating retrofit method using concrete. However, since the end of the existing shear wall must be broken as much as the rectangular steel tube's size and because the existing longitudinal rebars are cut, the material efficiency used is not high compared to the steel plate retrofit. It can be used for walls where wall end breaking is easy or for areas where excessive compressive force is expected. When subjected to lateral cyclic load, there is a high probability of a problem occurring because the flexural dominant section's failure is the concrete crushing at the end subjected to a compressive force.

In Figures 2 and 3, the flexural retrofit process using steel is expressed. (a) As the existing RC shear wall, the wall connected to the foundation was modeled. (b) The shear wall's end was broken to the required length, and preliminary work was performed to conceal the base plate into the concrete. For steel plate retrofit, the concrete cover thickness was chipped. In the steel tube retrofit, the wall end was broken by the steel tube's size. The base plate was for connecting the steel plate or the steel tube to the foundation or the slab. (c) This is the work of connecting the base plate to the foundation or the slab using a post-installed chemical anchor. It was required not only in the lower part but also in the upper part. The base plate was connected using four anchors. After that, the steel plate or the steel tube was placed on the base plate and connected to the existing shear wall using a post-installed chemical anchor. The steel plate and the steel tube needed to be perforated in advance to use the anchor. (d) The base plate and the steel plate or the steel tube were connected by welding. Since the welding line between the steel plate and the base plate was short, care was taken, as it could have split at the welded line when subjected to tensile force if not properly constructed. In the case of a steel tube, after welding the lower part, the non-shrink grout was filled into the steel tube through an injection pipe from the top. A slight gap occurred between the steel plate or the steel tube and the existing shear wall after retrofitting. It could be easily filled through liquid epoxy, but this was not a necessary procedure.

The difference between the steel plate and the steel tube was the buckling resistance due to the compressive force. As mentioned above, the highest bending stress was concentrated at the end, and buckling may have occurred in the steel. The steel tube had a higher moment of inertia due to its cross-sectional area and shape and had a high resistance to buckling because it was filled with non-shrink grout inside.

\subsubsection{Connection Methods}

The connection between the retrofit material and the existing wall was made using a post-installed chemical anchor. Post-installed chemical anchors are commonly used for concrete repair to connect retrofit materials to hardened concrete. It was observed that the process was properly performed by a simple method of inserting an anchor after perforating and cleaning holes of the existing concrete, injecting exclusive epoxy, and then inserting the anchor $[35,36]$. The longer the anchor length was, the higher the reliability was, but the maximum anchor length was limited. It was also possible to yield reinforcements subjected to tensile force, even with short development lengths of $300 \mathrm{~mm}$ or less. As a result of the study by Cho [31], the bond performance was sufficiently obtained, even at a shorter length than the development length of tensile deformed rebars suggested in $\mathrm{KBC}$ 
2016 [37] or ACI 318-19 [38]. Even in this case, no concrete cone-shaped failure or bond failure was observed. Therefore, it was designed based on the assumption that the epoxy's performance was sufficient to yield the rebar. Besides, since epoxy's characteristic bond strength is $15.3 \mathrm{MPa}$ in uncracked concrete provided by the manufacture [39], it was judged that there was no possibility of a problem occurring in the anchor.



Figure 2. Perspective view of shear wall flexural retrofit using steel tube.



(a)

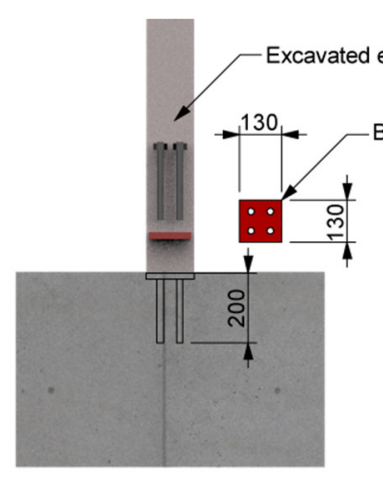

(b)



(c)

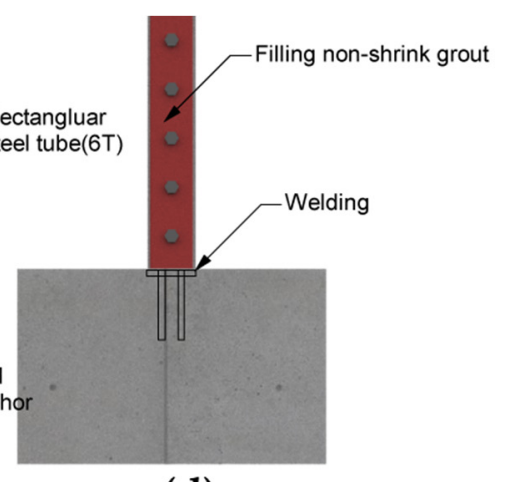

(d)

Figure 3. Elevations of flexural reinforcement using steel (a) existing wall; (b) installation of base plate; (c) installation of vertical retrofit material; (d) welding and filling grout.

\section{Experimental Plan}

\subsection{Retrofit Materials and Details}

In order to verify the performance of the flexural retrofit method for the RC shear wall using steel, an actual scale shear wall test was planned. The concrete compressive strength was determined to be $21 \mathrm{MPa}$, which was measured and calculated based on the concrete non-destructive test and core test results according to the building's safety evaluation to be retrofitted. The specimens were planned into three types: the existing wall, the steel plate retrofitted wall, and the steel tube retrofitted wall. The wall, which was judged to have insufficient flexural strength in structural analysis, was simulated in a non-retrofitted state and named "SOLID". The wall length was $1500 \mathrm{~mm}$, the height was $2600 \mathrm{~mm}$, and the thickness was $150 \mathrm{~mm}$. The "PLATE" specimen was a steel plate retrofitted wall after chipping the concrete cover thickness at both ends of the SOLID specimen. The "TUBE" specimen was a retrofitted wall that attached a steel tube after 
breaking both ends of the SOLID specimen as much as a steel tube's size. Longitudinal rebars were D13-400 MPa arranged in two layers at $350 \mathrm{~mm}$ intervals. In general, the RC shear wall's transverse rebars were laid at $150 \mathrm{~mm}$ intervals according to the wall's design drawing to be retrofitted, and the interval between the anchors connecting the steel retrofit material and the shear wall was set to $150 \mathrm{~mm}$ through the anchor design. Since the PLATE specimen was retrofitted after only peeling off the concrete cover at the wall end, the outermost end's longitudinal rebar was maintained. On the other hand, the TUBE specimen needed to be cut as much as the wall thickness to connect the rectangular steel tube, thus the longitudinal rebar at the outermost end was cut. Although the steel plate used in the PLATE specimen had a smaller retrofit material area than the steel tube used in the TUBE specimen, the PLATE specimen resisted bending together with the steel plate and the longitudinal rebar at the outermost wall end of the existing shear wall. Since the longitudinal rebar of the existing wall had a D13 diameter of $400 \mathrm{MPa}$ and the retrofitting steel's yield strength was $235 \mathrm{MPa}$, the difference in flexural strength between the two specimens was intended to be small. It was judged that the difference between the two specimens could be observed in the concrete crushing and the steel buckling at the wall end after reaching the maximum load. The details of materials and retrofit are shown in Table 2.

Table 2. Material and details of the specimens.

\begin{tabular}{|c|c|c|c|c|c|}
\hline Specimen & $\begin{array}{c}\mathrm{f}_{\mathrm{c}}^{\prime} \\
(\mathrm{MPa})\end{array}$ & $\begin{array}{c}\mathbf{f}_{\mathbf{y}} \\
\text { (Rebar/Steel) } \\
(\mathrm{MPa})\end{array}$ & Retrofit Material & $\begin{array}{l}\mathbf{P}_{\text {axial }} \\
(\mathbf{k N})\end{array}$ & $\begin{array}{l}\text { Breaking Length } \\
(\mathrm{mm})\end{array}$ \\
\hline SOLID & 21 & 400 & Non-retrofitted & \multirow{3}{*}{$\begin{array}{c}602.44 \\
(\mathrm{ALR}=15 \%)\end{array}$} & - \\
\hline PLATE & 21 & $400 / 235$ & Steel plate(9T) & & 20 \\
\hline TUBE & 21 & $400 / 235$ & Steel tube(6T) & & 150 \\
\hline
\end{tabular}

Notes: $\mathrm{f}_{\mathrm{c}}{ }^{\prime}$ : concrete nominal compressive strength, $\mathrm{f}_{\mathrm{y}}$ : steel and rebar nominal yield strength, $\mathrm{P}_{\text {axial }}$ : axial load, steel plate's width: $150 \mathrm{~mm}$, steel tube's size: $110 \times 110 \mathrm{~mm}$, yield strain of rebar and steel: $0.002(400 \mathrm{MPa}), 0.146$ (235 MPa). ALR: axial load ratio.

\subsection{Test Setting and Loading Protocol}

The plan of the specimen is shown in Figure 4. Compared to the SOLID specimen, the retrofitted specimens had a length shorter than $1500 \mathrm{~mm}$ before finishing. The PLATE specimen could be retrofitted with a short excavating length because the thickness of the steel plate $(9 \mathrm{~mm})$ and the concrete cover thickness were considered. Since the TUBE specimen had a rectangular steel tube $(110 \times 110 \mathrm{~mm})$, the concrete breaking length was longer than the PLATE specimen. After the retrofit was finished, a dry finish such as a gypsum board or a wet finish such as finishing grout could be used outside so that there was no difference before and after the retrofit. However, it was not finished to observe the behavior of the retrofit during the experiment.

On the upper part of the specimen, a loading beam was installed for axial and lateral loading. The axial load was applied to simulate the actual state during the flexural test using an oil jack installed from the top, and the load was distributed through the loading beam. The axial load ratio (ALR) was calculated as $15 \%\left(\right.$ ALR $\left.=\mathrm{P}_{\text {axial }} /\left(0.85 \times \mathrm{f}_{\mathrm{ck}} \times \mathrm{A}_{\mathrm{g}}\right) \times 100\right)$. The axial load applied to the general apartment structure was within $10 \%$ and rarely exceeded $10 \%$, even if the vertical extension was made to the top. The axial load was increased during the experiment by up to $15 \%$ to compensate for the axial load and consider earthquakes or wind.

By connecting an actuator for lateral loading and a loading beam, repeated cyclic loads were applied. The shear wall's lateral loading test was divided into a method of implementing a double curvature by fixing the upper and the lower parts and a method of implementing a single curvature in a cantilever type by fixing only the lower part. The double curvature's realization keeps the upper loading beam horizontal during lateral loading, but there are many cases where the loading beam is destroyed or the loading device and fixtures are damaged. Therefore, in this experiment, a cantilever type was 
selected in which the loading beam was placed at the free end. Even in this case, it was possible to implement the flexural behavior of the shear wall. However, in this case, out-ofplane behavior or torsion may have occurred, thus the experiment was performed after installing a guide to prevent this.

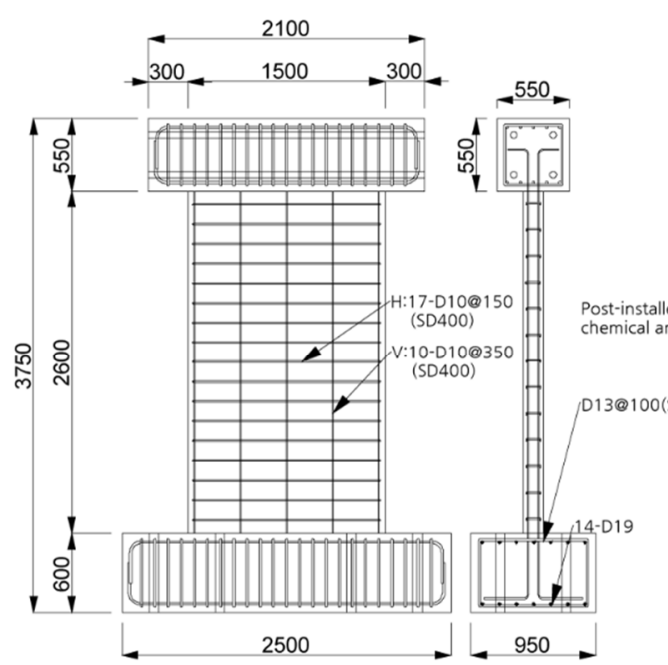

(a) SOLID



(b) PLATE

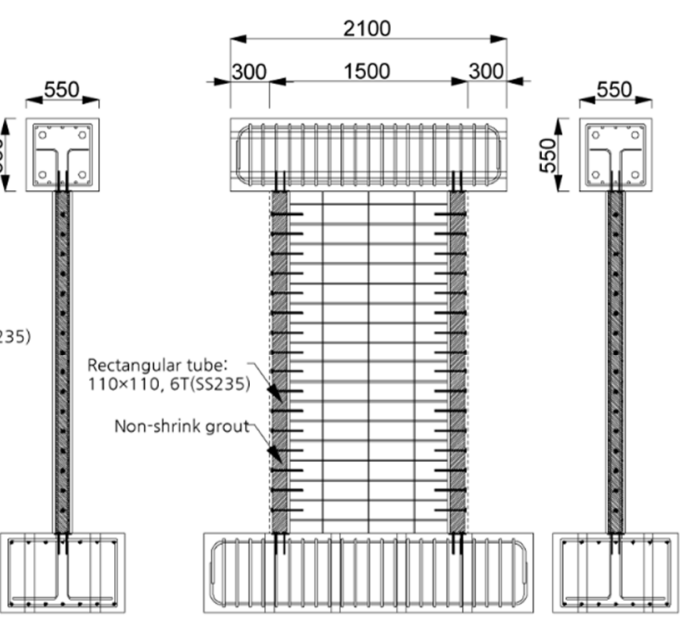

(c) TUBE

Figure 4. Elevations of the specimen.

A base with a length of $2500 \mathrm{~mm}$, a depth of $950 \mathrm{~mm}$, and a thickness of $600 \mathrm{~mm}$ was manufactured in the lower part, and the rebars were densely arranged to realize a fixed end. Eight large-diameter bolts fixed the foundation, and fixed hardware was used on both sides to prevent lifting or sliding during the experiment. A displacement transducer was installed to measure the movement of the foundation to eliminate the error. After setting the specimen, $15 \%$ of ALR was loaded using an oil jack, and then lateral loading was performed. The lateral loading was made in the displacement controlled, and the drift ratio increased to $0.25 \%$ for the elastic zone and initial crack observation and then increased in the order of $0.5 \%$ and $1 \%$. The experimental setting is shown in Figure 5.


Figure 5. Test setting scheme of cantilever-type shear wall lateral loading.

\subsection{Sectional Analysis}

The sectional flexural analysis was performed based on the specimen's cross-section, as shown in Figure 6. The specimens' cross-section was divided into $1 \mathrm{~mm}$ intervals using a CAD program, and each piece was classified by the material. Furthermore, the area and 
the centroid position of the pieces were calculated. After that, the equilibrium state was found while moving the neutral axis through iteration. It is a useful method because it can assemble a constitutive equation for each material separately and determine the bending history to the ultimate state. The cross-section of each specimen is shown at the top of Figure 6, and the moment-curvature relationship and the neutral axis depth-curvature relationship derived from the cross-sectional analysis are shown below.

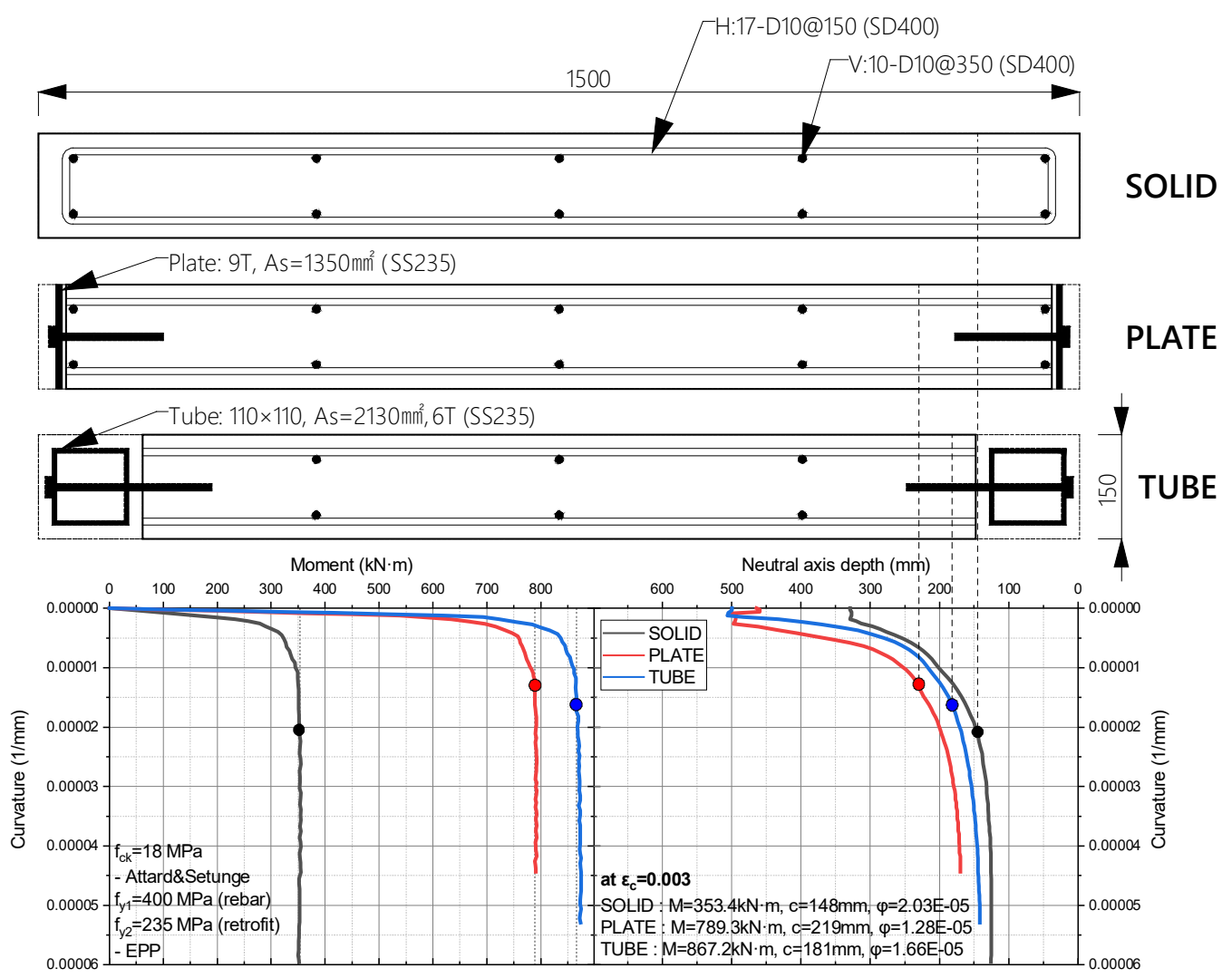

Figure 6. Results of cross-sectional analysis of the specimen. Cross-section (top); moment-curvature and neutral axiscurvature relationship (bottom).

The Attard and Setunge model [40] was used for the concrete compression model, and the tensile area was ignored. Rebar and steel were assumed to be the elastic perfectly plastic materials, and tensile hardening was not considered. Since the anchor or the rebar were completely attached, there was no slip between the retrofit materials and the existing wall, and there was no failure at the upper and the lower anchors or the welding. The retrofit steel was SS235 steel with a yield strength of $235 \mathrm{MPa}$, and $1350 \mathrm{~mm}^{2}$ was attached to each end of the PLATE, and $2130 \mathrm{~mm}^{2}$ was attached to the TUBE. The retrofit end of the TUBE specimen was filled with non-shrink grout to resist compression effectively. The compressive strength of the non-shrink grout was $60 \mathrm{MPa}$, and the manufacturer's data were used.

As a result of the cross-sectional analysis, the SOLID showed a moment of $353.4 \mathrm{kN} \cdot \mathrm{m}$, and the neutral axis depth was $148 \mathrm{~mm}$. The retrofitted PLATE specimen presented a moment of $789.3 \mathrm{kN} \cdot \mathrm{m}$, the neutral axis depth was $219 \mathrm{~mm}$, and the flexural strength increased by $123 \%$ compared to the SOLID specimen, while neutral axis depth increased $71 \mathrm{~mm}$. The TUBE specimen exhibited a moment of $867.2 \mathrm{kN} \cdot \mathrm{m}$ and had the highest retrofit effect. The neutral axis depth slightly decreased to $181 \mathrm{~mm}$, but the flexural strength increased by $145 \%$ compared to the SOLID specimen. When the tensile force at the outermost rebar and the steel yield was simply calculated, the tensile force when the PLATE specimen's rebar and steel plate at the wall end were summed was $418.5 \mathrm{kN}$. If only the tensile force was calculated at the TUBE specimen's steel tube yielding, it was $500.6 \mathrm{kN}$, 
which was about $20 \%$ higher than that of the PLATE specimen. Additionally, since the distance from the neutral axis to the centroid was shorter than that of the PLATE specimen, it seems reasonable that the sectional analysis shows that the TUBE specimen was about $10 \%$ higher than that of the PLATE specimen. However, the confinement effect of the steel tube filled with non-shrink grout could not be accurately reflected in the cross-sectional analysis, but it was judged that higher performance in ductility and strength could be observed from the wall end of the TUBE specimen during the experiment. Therefore, it was expected that the retrofit effect of the retrofitted specimens would develop without any problem if the previously assumed anchor or weld did not fail or slip. The point plotted in the graph was a state where the outmost concrete compression strain was 0.003 . The dotted lines connecting the section and the neutral axis-curvature relationship represent each section's neutral axis position. The part that bore the compressive force in the entire wall was only about $10-15 \%$, and the rebars or the retrofit material bore almost all the compressive force at the end. In the case of the TUBE specimen, the neutral axis was located between the wall and the retrofit, thus it was considered that there was a possibility that bond failure may have occurred due to in-plane vertical shear.

\section{Result}

\subsection{Load-Displacement Relationship}

As a material test result of concrete, rebar, and steel used in the experiment, the results exceeded the target $21 \mathrm{MPa}$ of the compressive strength, $400 \mathrm{MPa}$, and $235 \mathrm{MPa}$ of the yield strength. The average compressive strength of concrete was $22.7 \mathrm{MPa}$. The rebar was measured 50-90 MPa higher than the nominal yield strength, and the steel was $20-50 \mathrm{MPa}$ higher, which was within the range specified in the test standard [41].

The lateral loading test results of the shear wall specimen are shown in Table 3 and Figure 7. Compared to the existing wall, the flexural strength of the retrofitted specimen was increased, and, in the case of the TUBE specimen, the ductility was remarkably improved compared to the existing wall. The maximum load of the SOLID specimen (existing wall) was $257.6 \mathrm{kN}$ and $250.94 \mathrm{kN}$. In this result, compared to $135.92 \mathrm{kN}$, which was the cross-sectional analysis result, a large error occurred with a $190 \%$ load. The difference between the cross-sectional analysis of the SOLID specimen and the test result was considered due to the negligence to properly simulate the $15 \%$ ALR in the crosssectional analysis, underestimating concrete deformation capacity and the failure to reflect the tensile hardening behavior of rebars. In the PLATE specimen, the maximum load was $325.63 \mathrm{kN}$ in positive loading and $322.99 \mathrm{kN}$ in negative loading. Compared to the sectional analysis results, the maximum load could be predicted slightly, with $107 \%$ and $106 \%$. In the TUBE specimen case, the positive loading force was $298.78 \mathrm{kN}$, and the negative force was $311.68 \mathrm{kN}$, and the load was reduced compared to the PLATE specimen. Compared to the cross-sectional analysis, it was $90 \%$ and $93 \%$, which was lower than the analysis result. Unlike the cross-sectional analysis, the TUBE specimen's flexural strength was lower than that of the PLATE specimen, which appeared to be due to the anchor's bond failure connecting the base plate with the steel tube and the foundation. The displacement ductility ratio was calculated by comparing the yield point of the outermost tensile rebar or retrofit material and the maximum $80 \%$ load. It was calculated as $4,8,16$ in the order of SOLID, PLATE, and TUBE. As shown in the load-displacement relationship, the maximum load was reached at the drift ratio $1 \%$ in the TUBE specimen, and the load gradually decreased.

On the other hand, in the SOLID specimen and the PLATE specimen, the load rapidly decreased after reaching the maximum load. The maximum displacement also experienced up to $5 \%$ of the TUBE specimen compared to $2 \%$ of the SOLID specimen. As expected, it was judged that the highest displacement ductility ratio was due to the high compression resistance of the steel tube filled with non-shrink grout retrofitted at the wall end of the TUBE specimen. 
Table 3. Comparison between test and analysis result.

\begin{tabular}{|c|c|c|c|c|c|}
\hline \multirow{2}{*}{ Specimen } & \multirow{2}{*}{$\begin{array}{l}\text { Retrofit } \\
\text { Material }\end{array}$} & \multicolumn{2}{|c|}{ Lateral Load } & \multirow{2}{*}{$\begin{array}{c}\mathbf{P}_{\text {exp }} / \mathbf{P}_{\text {sec }} \\
(\%)\end{array}$} & \multirow{2}{*}{ Displacement Ductility Ratio } \\
\hline & & $\begin{array}{l}P_{\exp } \\
(k N)\end{array}$ & $\begin{array}{l}P_{\text {sec }} \\
(\mathbf{k N})\end{array}$ & & \\
\hline \multirow{2}{*}{ SOLID } & \multirow{2}{*}{-} & 257.6 & \multirow{2}{*}{135.92} & 190 & 4 \\
\hline & & 250.94 & & 185 & 4 \\
\hline \multirow{2}{*}{ PLATE } & \multirow{2}{*}{ Steel plate (9T) } & 325.63 & \multirow{2}{*}{303.58} & 107 & 8 \\
\hline & & 322.99 & & 106 & 8 \\
\hline \multirow{2}{*}{ TUBE } & \multirow{2}{*}{ Steel tube (6T) } & 298.78 & \multirow{2}{*}{333.54} & 90 & 16 \\
\hline & & 311.68 & & 93 & 16 \\
\hline
\end{tabular}

Notes: $\mathrm{P}_{\text {exp }}$ : maximum lateral load by experiment, $\mathrm{P}_{\text {sec }}$ : maximum lateral load by sectional-analysis, displacement ductility: displacement at $80 \%$ of the maximum load/yielding of the outermost tensile rebar or steel.



(a) Backbone curves

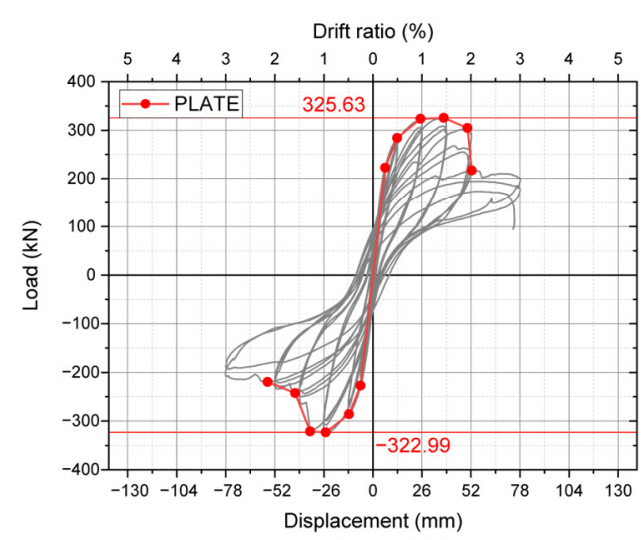

(c) PLATE

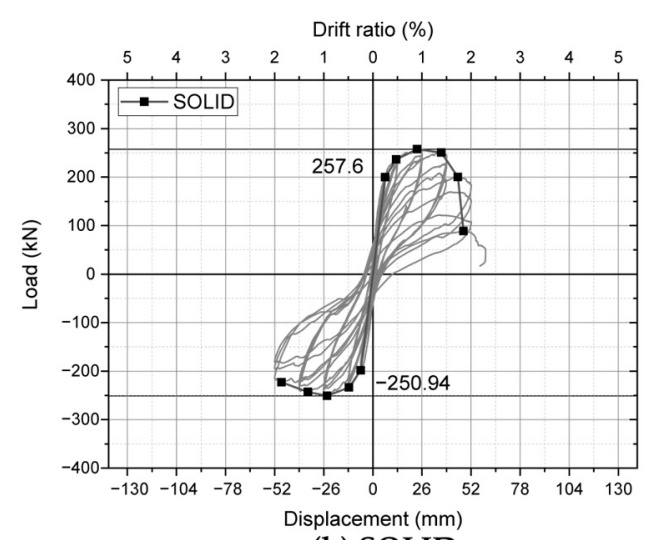

(b) SOLID

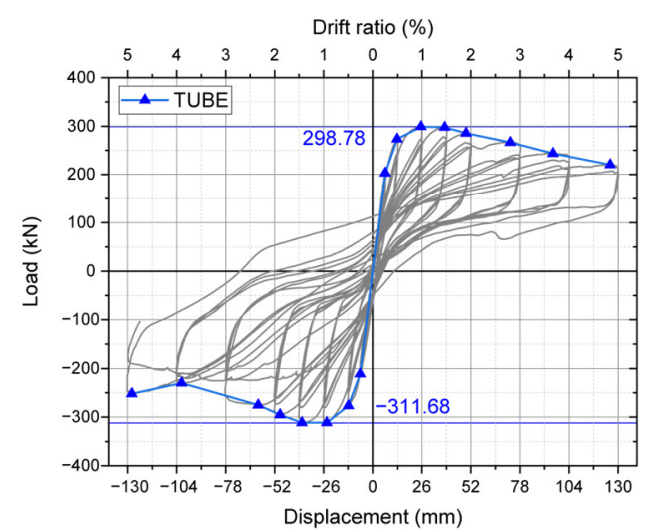

(d) TUBE

Figure 7. Load-displacement relationship.

In the SOLID specimen, the test result was 185-190\% higher than that of the crosssectional analysis result, whereas the cross-sectional analysis result and the test result were almost similar in the retrofitted specimens. In the PLATE specimen, it was only about $6-7 \%$ high, and the result of the TUBE specimen was somewhat reduced by $10 \%$. The strength of the PLATE and the TUBE specimens was not as expected, but the displacement ductility increased as expected. Commonly, the ductility decreases as the flexural retrofit increases. However, due to the experiment, the ductility increased as the retrofit amount increased, representing that the retrofit effect against tensile force was small, and the retrofit effect against compression was high. In the load-displacement relationship in Figure 7 , the difference between the SOLID specimen and the PLATE specimen appears to be insignificant. However, the displacement ductility ratio was different because it determined the rebar yield point and the $80 \%$ drop point compared to the maximum 
load. In particular, the TUBE specimen's retrofit was one of the most effective composite structures for compressive force in the form of CFT.

\subsection{Crack Pattern}

Figure 8 shows the crack pattern for each specimen. One cell was $250 \mathrm{~mm}$ long and was drawn on the surface of the specimen before the experiment to determine the location of the crack easily. The SOLID specimen showed a typical flexural failure pattern. In the drift ratio $2 \%$, a rapid load reduction was observed. As a load of less than $100 \mathrm{kN}$ was acquired, crushing occurred at the compression edge, and buckling of the outermost longitudinal rebar was observed. In the case of the PLATE specimen, a similar pattern to that of the SOLID specimen appeared. At the drift ratio $2 \%$, a rapid load reduction was observed as was buckling of about $2 \mathrm{~mm}$ between the anchors in the lower part. After that, a load of $200 \mathrm{kN}$ was expressed by applying up to $3 \%$ of the drift ratio, and a concrete crushing was observed. Compared to the SOLID specimen, cracks or peeling were concentrated in the lower part. A peculiar crack pattern was observed in the TUBE specimen. A crack was observed between the steel tube and the existing wall during the lateral loading, but there was no flexural crack on the existing wall's surface as in the SOLID specimen until the maximum load was reached. After reaching the maximum load, horizontal and vertical cracks appeared in the lower part, but the cracks did not progress. Additionally, a cone-shaped crack was observed around the anchor connecting the steel tube and the existing wall, and the experiment was terminated, as the concrete below the height of about $550 \mathrm{~mm}$ was abruptly split in the second cycle of $5 \%$ drift ratio. In the crack pattern, typical flexural or shear cracks were not observed, and the shear wall behavior seemed to be concentrated on rocking, a phenomenon that the wall was separated and lifted from the foundation. As shown in Figure 8c, the lower part's concrete was destroyed as it split back and forth in the middle of the thickness direction up to the lower two compartments below the height of $550 \mathrm{~mm}$.

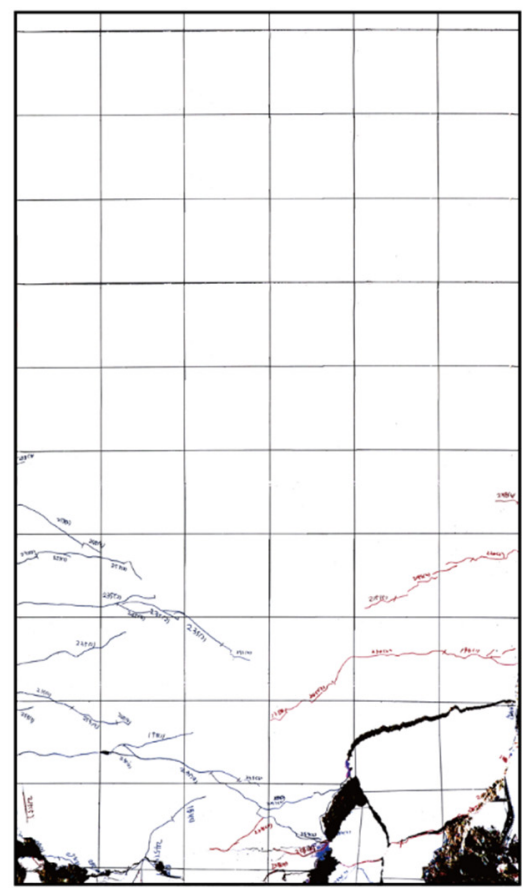

(a) SOLID

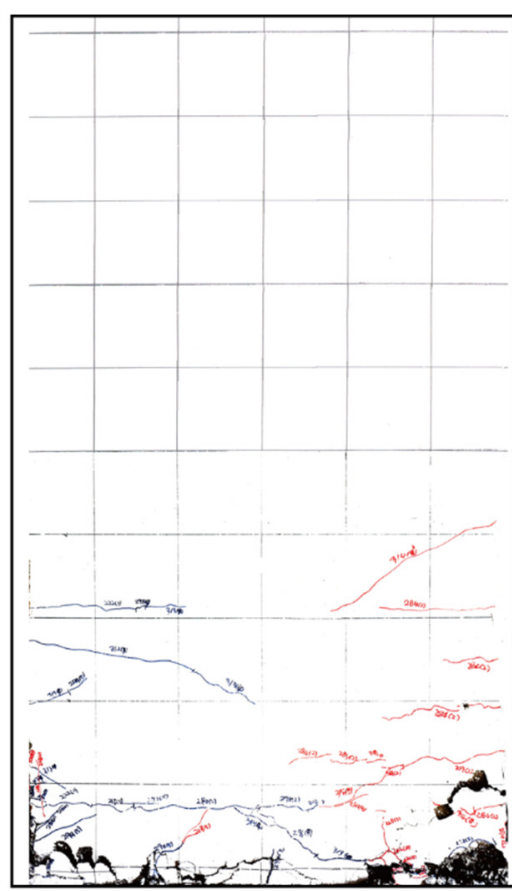

(b) PLATE

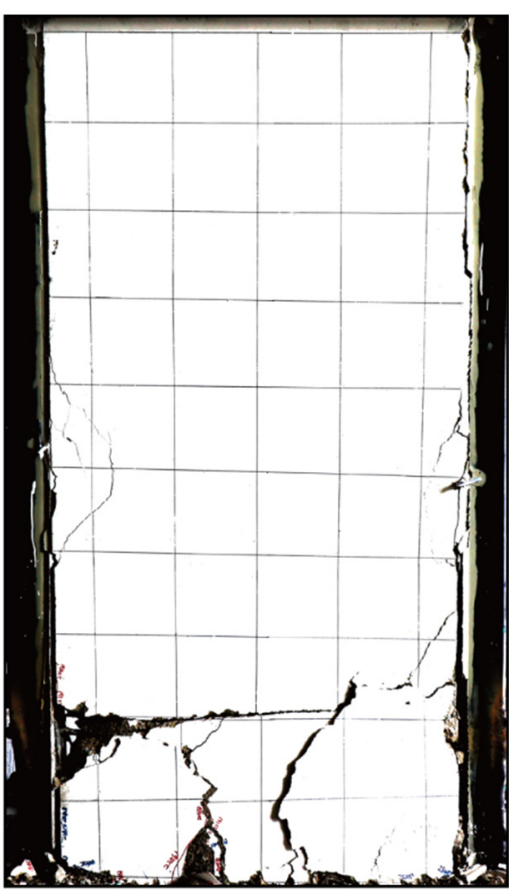

(c) TUBE

Figure 8. Crack pattern of specimens after experiment.

\subsection{Stiffness Degradation}

The stiffness degradation of the specimens is shown in Figure 9a. There was little difference in stiffness between the positive loading and the negative loading in each 
specimen. The initial stiffness was expected to be the highest in the TUBE specimen retrofitted with a steel tube with the highest moment of inertia, but the PLATE specimen's stiffness was the highest. Then, TUBE and SOLID specimens appeared in order. This expresses that the TUBE specimen showed a rocking phenomenon from the initial drift ratio compared to the PLATE specimen. When rocking occurred, stress was concentrated on the rebars and the anchors that connected the foundation and the wall, and if the anchor did not properly develop, the stiffness was inevitably low. As is described later, this was judged to be a problem in the lower part of the TUBE specimen's anchor length. Near the drift ratio $1.5 \%$ to $2 \%$, the PLATE specimen's stiffness was lowered more than that of the TUBE specimen, and it was destroyed soon. Simultaneously, the steel plate's buckling attached to the PLATE specimen was observed, and the concrete at the wall end was crushed. Until the steel plate's buckling occurred, the steel plate shared the compressive force with the concrete, but it was supposed to be destroyed as the compressive stress concentrated on the concrete due to the steel plate's buckling.



(a)

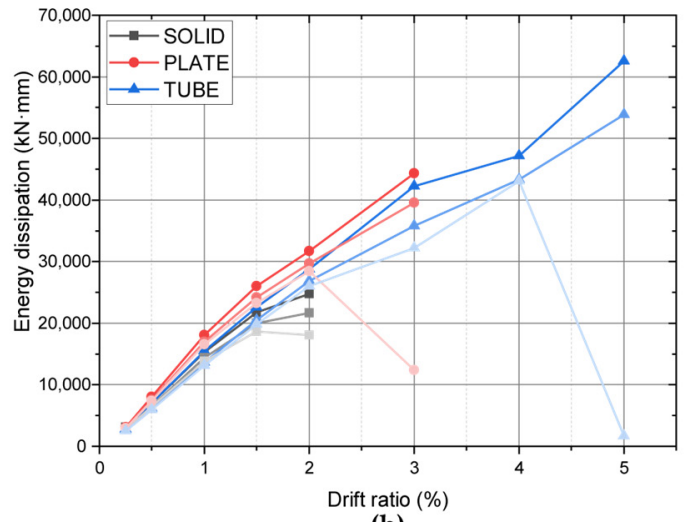

(b)

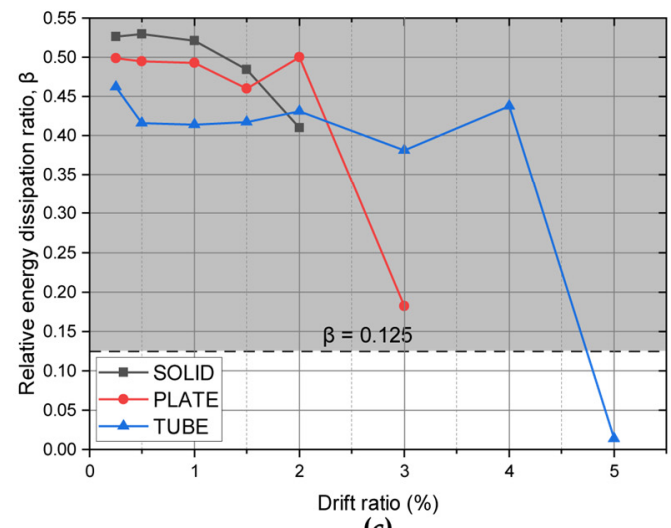

(c)

Figure 9. (a) Stiffness degradations; (b) energy dissipations; (c) relative energy dissipation ratios.

\subsection{Energy Dissipation}

The energy dissipation is shown in Figure 9b. The darkest color is the first cycle of each drift, and the third cycle is the lightest color. Up to the drift ratio $2.5 \%$, the PLATE specimen's energy dissipation was the highest, but it was soon destroyed. The TUBE specimen was destroyed while dissipating energy up to the drift ratio $5 \%$, thus the cumulative energy dissipation was the highest. At the drift ratio $2.5 \%$, the TUBE specimen's energy dissipation increased compared to that of the PLATE specimen. In the SOLID specimen case, it was similar to the TUBE specimen until the drift ratio $1.5 \%$, but it decreased as it was destroyed. In the SOLID and the PLATE specimens, the difference in energy dissipation per cycle was the largest immediately before the failure. However, the difference between the first and the second cycles of the drift ratio $5 \%$ was about $14 \%$ in the TUBE specimen, but rapid destruction occurred in the third cycle. 
ACI ITG-5.1 [42] requires the relative energy dissipation ratio (REDR, $\beta$ ), defined as the ratio of the specimen's ideal energy dissipated during a complete cycle. The REDR is the value obtained by dividing energy dissipation of the third cycle by the parallelogram area drawn by load, displacement, and initial stiffness of the first cycle. The REDR is a measure of the amount of viscous damping in an equivalent linear-elastic system that would result in a similar amount of energy dissipation as the nonlinear system. There may be inadequate damping for the structure, and the oscillations of the structure may continue for some time after an earthquake, possibly leading to low-cycle fatigue effects and excessive displacements $[43,44]$. Additionally, the REDR value is required to be greater than $1 / 8(12.5 \%)$ in the complete third cycle above the validation-level drift ratio. The height-to-length ratio determines the validation-level drift ratio, and when applied to the specimens, this value was $1.916 \%$ of the drift ratio. Figure 9c shows that the REDR values of all the specimens met the minimum condition, as the result values were in the gray area. The TUBE specimen was destroyed during the third cycle at a drift ratio of $5 \%$, thus it was excluded from the REDR calculation.

\section{Discussion}

The retrofit effect of the flexural retrofit using steel was not derived as expected. As shown in Table 4, a flexural retrofit effect of more than $100 \%$ was expected by cross-sectional analysis, but the experiment results only increased the maximum load by $16-29 \%$. In the TUBE specimen case, the maximum load was lower than that of the PLATE specimen, even though the retrofit amount was increased considering the removal of the outermost longitudinal rebar due to wall end breaking (4-D10). On the other hand, the displacement ductility ratio was improved two times for the PLATE specimen and up to four times for the TUBE specimen compared to the existing wall. The retrofit effect that could be inferred through this is that it was effectively applied to the compressive force. According to the manufacturer's technical data, the retrofit was developed with four post-installed chemical anchors on the top and the bottom. As the lower anchor part was observed in a state separated from the foundation after the end of the experiment, it was judged that the chemical anchor's performance was not properly expressed.

For this reason, in the TUBE specimen, a steel tube with a higher inertia moment of the cross-section was used compared to the steel plate, and the inside was filled with non-shrink grout. Although the retrofit's upper and lower bond performance was not adequately expressed, it was possible to resist the compression force even though it could not properly resist tensile force. The steel plate was easily lost due to buckling when the compressive force was concentrated at the wall end, but in the steel tube, it could effectively resist even high compressive force, and the internal non-shrink grout could present higher compressive performance due to the confinement effect as with the CFT.

Table 4. Flexural retrofit effect verification using steel.

\begin{tabular}{|c|c|c|c|c|c|c|}
\hline \multirow{2}{*}{ Specimen } & \multirow{2}{*}{ Retrofit Material } & \multirow{2}{*}{$\begin{array}{c}A_{\mathrm{s}, \text { retrofit }} \\
\left(\mathrm{mm}^{2}\right)\end{array}$} & \multicolumn{2}{|c|}{$\mathbf{P}_{\text {retrofit }} / \mathbf{P}_{\text {SOLID }}$} & \multirow{2}{*}{$\begin{array}{c}D_{\text {retrofit }} / D_{\text {SOLID }} \\
(\%)\end{array}$} & \multirow{2}{*}{$\begin{array}{c}\text { Excavating Length } \\
(\mathrm{mm})\end{array}$} \\
\hline & & & $\begin{array}{l}\text { Exp } \\
(\%)\end{array}$ & $\begin{array}{l}\text { Sec } \\
(\%)\end{array}$ & & \\
\hline SOLID & - & - & $\begin{array}{l}100 \\
100\end{array}$ & 100 & 100 & - \\
\hline PLATE & Steel plate(9T) & 1350 & $\begin{array}{l}126 \\
129\end{array}$ & 223 & 200 & 20 \\
\hline TUBE & Steel tube(6T) & 2130 & $\begin{array}{l}116 \\
124\end{array}$ & 245 & 400 & 150 \\
\hline
\end{tabular}

Notes: $\mathrm{A}_{\mathrm{s} \text {,retrofit }}$ : amount of retrofitted steel, $\mathrm{P}_{\text {retrofit }} / \mathrm{P}_{\mathrm{SOLID}}$ : maximum load of retrofitted specimen $/$ maximum load of existing wall, $\mathrm{D}_{\text {retrofit }} / \mathrm{D}_{\text {SOLID }}$ : displacement ductility ratio of reinforced specimen/displacement ductility ratio of existing wall.

Another reason why the TUBE specimen's retrofit material did not effectively resist the tensile force was the crack pattern. As shown in Figure 8c, almost no cracks on the wall surface occurred before reaching the maximum load, and cracks were concentrated in 
the connection part between the steel tubes and the existing wall. In particular, the major crack that occurred horizontally at the height of $550 \mathrm{~mm}$ from the bottom was the part where the post-installed chemical anchor was located, and after it was destroyed, it was damaged to the extent that all the chemical anchors were exposed. If it resists the tensile force effectively, cracks must occur due to flexural tensile stress. The retrofit material was peeled off by compression from the existing wall, and the lower part of concrete in the existing wall was split. Besides, it was judged that the transverse rebar of the existing wall was cut in the wall end to maintain the shear wall's length, and the development was lost. If the transverse rebars were not cut like the SOLID and the PLATE specimens, the wall splitting failure pattern like the TUBE specimen would not have been observed.

Figure 10a shows the failure of the steel tube-existing wall connection observed after the end of the experiment of the TUBE specimen. Rectangular steel tubes filled with non-shrink grout at the ends were retrofitted, and this retrofit was connected to the existing wall using post-installed chemical anchors. Figure $10 \mathrm{~b}$ is the rocking observed during the experiment after bond failure at the anchors to connect between the steel tube and the foundation. Post-installed chemical anchors were attached at $150 \mathrm{~mm}$ intervals in the middle of the wall thickness, and it seemed to damage the existing wall with retrofitted undergoing repeated cyclic loads. Additionally, unlike the SOLID or the PLATE specimens, there was no out-of-plane transverse rebar, thus it was considered that the splitting failure of the existing wall occurred. In the TUBE specimen, the length was reduced to $80 \%$ of the existing wall's length to attach the rectangular steel tube as the retrofit material. If the retrofit material and the existing wall were separated, the transverse rebars in the existing wall from which the development part was cut were the only shear reinforcements in the specimen. The lower part of the shear wall was split along the anchor line in the wall's thickness direction, and cracks occurred horizontally along the anchor recess. Anchors were embedded between the rebars to minimize the effect on the transverse rebars of the existing wall, however, the anchors were not constrained in the out-of-plane and the in-plane directions, which seemed to be fatal. In the PLATE specimen retrofitted with steel plate, no damage occurred around the anchor recess. This seemed to be the effect of the stiffness of the retrofit material. In the rectangular steel tube, the stress was concentrated due to high stiffness, and it was judged that a problem occurred between the steel tubes and the existing wall.

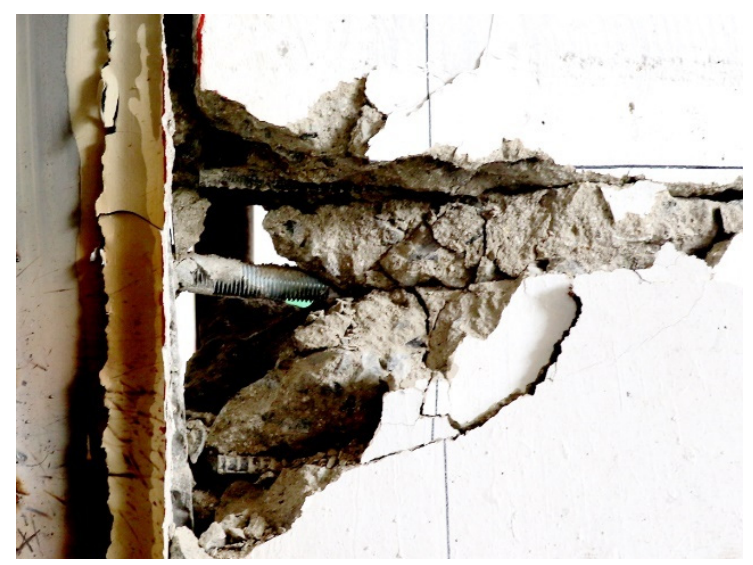

(a)



(b)

Figure 10. Damage around the anchor of TUBE specimen. (a) Damage to anchor part between steel tube and existing wall; (b) Retrofit-foundation bond failure (estimated pull-out failure).

Figure $10 \mathrm{~b}$ shows the retrofit pull-out failure due to the wall lifting phenomenon observed during the experiment. The shear wall was a specimen with a considerable depth, and due to the characteristic of separating the foundation and the wall, an inevitable separation occurred between the wall and the foundation during lateral loading, which 
is called the rocking phenomenon [45]. The retrofit material must be connected to a horizontal member such as a foundation or a slab for the shear wall's flexural retrofit. Cracks in flexural proceed from the portion subjected to tensile force, and if the retrofit for tension is insufficient, the cross-section's performance becomes inefficient. In the retrofitted specimens, four post-installed chemical anchors were constructed using HILTI HY200, but when tension was applied, all anchors were pulled out. This phenomenon was observed in both retrofits in positive loading and negative loading. Accordingly, the tensile force was burdened by the six longitudinal rebars remaining in the existing wall, and as the lateral displacement increased, it began to fracture, and the experiment ended with two remaining at the drift ratio $5 \%$.

On the other hand, in the PLATE specimen, bond failure did not occur, and the rocking phenomenon was shallower than the TUBE specimen. However, at the drift ratio $2 \%$ where the PLATE specimen was destroyed, the load was rapidly decreased as the welding between the base plate and the steel plate was broken. Though, in a previous study by Cho [31], in the case of development of SD500 rebar (yield strength $500 \mathrm{MPa}$ ) using the epoxy for the post-installed chemical anchor, the yield of the rebar was observed even with a development length of about $300 \mathrm{~mm}$, thus the bond performance of the post-installed chemical anchor itself and the construction process needs to be reviewed.

The bond strength of the epoxy for the post-installed chemical anchor was $15.3 \mathrm{MPa}$. Four of these anchors were used, the diameter of the anchor was M20, and the anchor length was $215 \mathrm{~mm}$. The nominal bond strength of an anchor under tension could be calculated using the equation of ACI 318-19 17.6.5.1b. Each anchor's bond strength, which reflects edge distance, thickness of foundation, eccentrical effect, and strength reduction factor $(\varnothing=0.65)$ [39], was $187.67 \mathrm{kN}$. Even if all tensile forces were concentrated on the anchors, when the maximum load derived from the test result was converted into the wall's height and length, it was less than the anchors' total bond strength $(750.68 \mathrm{kN})$. As a result, the anchor design was correctly done, but it seems that the bond performance was not adequately expressed. The possibility that the bond strength of the epoxy may not have developed properly was due either to the fact that the perforated part was not appropriately cleaned, leaving foreign matters, or the epoxy was injected while the water was filled inside the perforated part, or the epoxy could not be filled by the air bubbles when the anchor was inserted. In this specimen, it was judged that the debris was not properly cleaned during drilling. In recent manufacturer's manuals, a hollow carbide drill bit is used to inhale simultaneously as perforation, leaving almost no foreign matter inside the perforated part. Besides, before epoxy injection, the perforated part is cleaned one more using an iron brush and a hammer drill so that there is no residue. However, in the cleaning before epoxy injection of these specimens, only dust was blown out using a blower according to the previous manual before applying the suction cleaner. In the future, it is expected that it will be necessary to verify the anchor direct tensile test in a similar environment, and it is considered that the details of the anchor and the weld at the wall end need to be improved.

Figure 11 compares the total lateral displacement and the lateral displacement caused by the TUBE specimen's rocking. The angle caused by the wall's rocking was replaced by the lateral displacement using the wall's height. In the case of the general flexural dominant shear wall, it appeared at the level of $10-20 \%$ of the total, but in the case of the TUBE specimen, it was about $12-17 \%$ at the initial drift, but it gradually increased as the experiment progressed, reaching $67 \%$ at the drift ratio $3 \%$. Initially, the bond between the retrofit and the foundation was expressed, but it was judged that the wall did not bend and lifted as the end retrofit was pulled out, as observed in Figure 10b. The result, which appeared to have a ductile behavior derived from the load-displacement relationship, appeared to be the interaction between the axial load (ALR $=15 \%)$ from the top and the lateral load applied according to the overall movement of the wall. In this process, the retrofit appeared to resist only compression, with little resistance to tension. The TUBE specimen's retrofit is similar to a small CFT column, thus it resists compression very 
effectively. Accordingly, the test was not terminated due to the crushing of the wall end concrete and the rebar or the steel buckling as with the SOLID or the PLATE specimens, and the ultimate failure was delayed because the compressive force was concentrated on the rectangular steel tube.

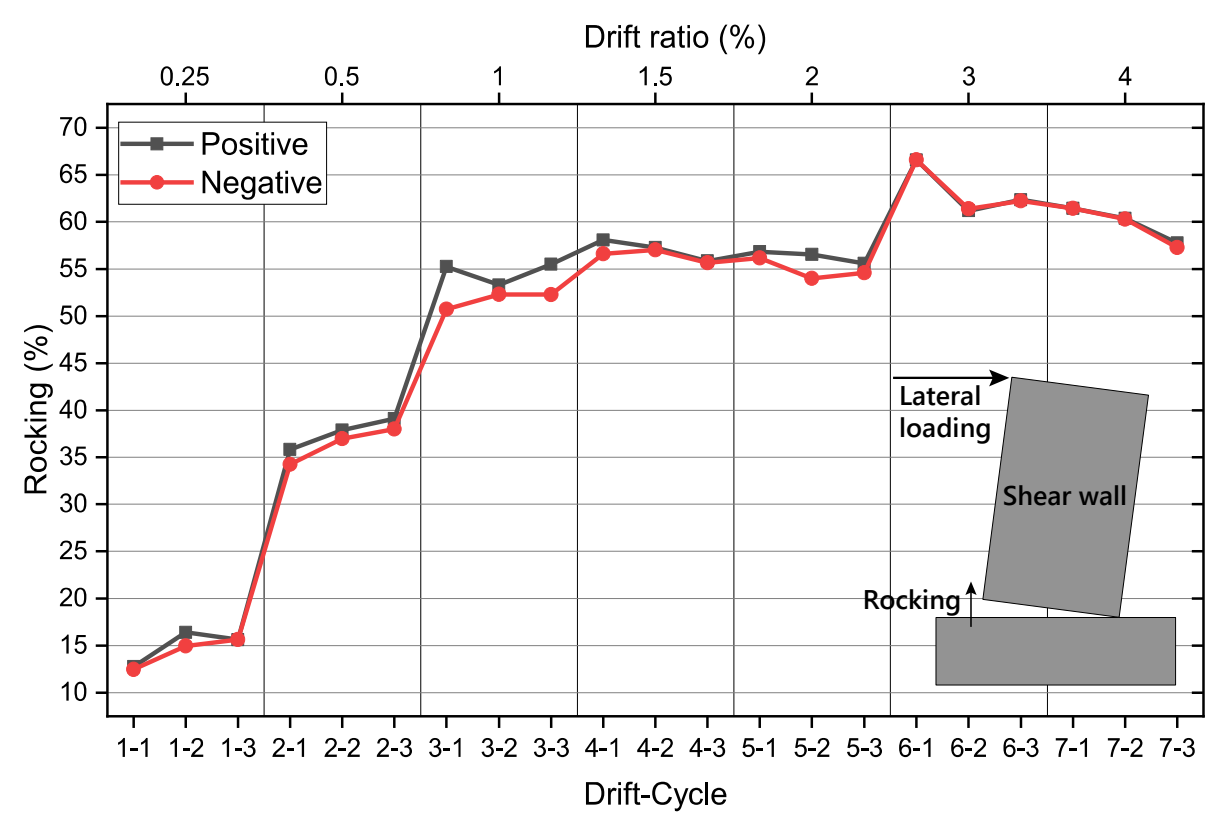

Figure 11. Comparison of lateral displacement caused by wall rocking and total lateral displacement of TUBE specimen.

\section{Conclusions}

In this study, the flexural retrofit method of the RC shear wall using steel was developed, and the retrofit effect was verified by applying it to the shear wall and experimenting with it. A retrofit method was specified that effectively resists flexural by breaking the wall ends of the shear wall as necessary and attaching a steel plate or a rectangular steel tube, and the size of the wall does not change before and after retrofitting. Based on this, it is considered that the details of improved flexural retrofit can be developed in the future. The conclusions derived from this study are as follows:

1. The flexural strength of shear walls can be increased to $16-29 \%$ through flexural retrofit using steel. Additionally, the shear wall's displacement ductility ratio can be improved up to $200-400 \%$. In the retrofitted wall through sectional analysis, the maximum load could be predicted within $10 \%$ of the error range. However, it was found that the expected analysis result for the existing wall underestimated the experimental result, and, accordingly, the retrofit effect was not sufficiently expressed compared to the experimental result of the existing wall.

2. The flexural retrofit to exhibit adequate performance must be sufficiently attached to the existing wall, foundation, and slab. If a post-installed chemical anchor is used on a $150 \mathrm{~mm}$ thick wall subjected to repeated cyclic loads, it may cause large cracks or severe damage. In this case, it seems that the transverse rebars of the existing wall should be preserved as much as possible, or the connection method with the retrofit material should be considered. It is also observed that the anchor connecting the retrofit material and the foundation is pulled out when under tension, thus it is necessary to reconsider the anchor design and the construction process.

3. The existing wall and the wall retrofitted with steel plate resulted in flexural cracks, and it was finally destroyed by the concrete crushing and the rebar or the steel plate buckling. When retrofitted with the steel plate, there was no problem with the anchor, but the weld line between the base plate at the upper part and the steel plate was broken just before the failure. Since there is a restriction on the weld length between 
the steel plate and the base plate, it is judged that the connection method needs to be supplemented.

4. The result of the wall retrofitted with steel tubes is judged to be a combination of the anchor's bond failure and the cutting of the transverse rebar of the existing wall. Due to the bond failure of the anchor connected to the foundation, the steel tube bore only the compressive force, and, as a result, vertical cracks occurred along the anchor line connecting the steel tube to the existing wall on the side of the wall, rather than the horizontal flexural crack on the surface of the existing wall. If there was out-of-plane transverse rebar, it could have resisted vertical cracking, but because it was cut at the wall end of breaking, splitting failure occurred. Therefore, it is necessary to find a method of not cutting the existing wall transverse rebar when retrofitting steel tubes or preserving part of the transverse rebar and connecting it by welding as with the excavating retrofit method.

The flexural retrofit using steel has a significant advantage over the existing retrofit method. If the construction method identified in this study is supplemented, it is expected to be an effective flexural retrofit method. The connection between the existing wall and the retrofit can be solved by welding between the steel and the transverse rebars, and the connection between the steel and the foundation or the slab can be improved by using highstrength steel or high-performance chemical anchors. There is a need to verify the bond strength and the construction procedure through a direct pull-out test before construction on the actual shear wall to prevent the anchor's bond failure connected to the foundation.

Author Contributions: Formal analysis, U.C.; Investigation, U.C.; Supervision, C.-S.C.; Validation, J.-H.C. and B.-I.B.; Writing-Original draft, S.-Y.K.; Writing-Review \& editing, C.-S.C. All authors have read and agreed to the published version of the manuscript.

Funding: This research was funded by the National Research Foundation of Korea (NRF) grant funded by the Korea government (MSIT), grant number NRF-2020R1A4A1019074, and the Korea Agency for Infrastructure Technology Advancement (KAIA) grant funded by the Ministry of Land, Infrastructure and Transport, grant number 20RERP-B100006-06.

Institutional Review Board Statement: Not applicable.

Informed Consent Statement: Not applicable.

Data Availability Statement: Data is contained within the article.

Conflicts of Interest: The authors declare no conflict of interest.

\section{References}

1. Ireland, M.G.; Pampanin, S.; Bull, D.K. Concept and Implementation of a selective Weakening Approach for the Seismic Retrofit of RC buildings. NZSEE 2006.

2. Ireland, M.G.; Pampanin, S.; Bull, D.K. Experimental Investigations of a Selective Weakening Approach for the Seismic Retrofit of R.C. Wall. NZSEE 2007.

3. Kam, W.Y.; Pampanin, S.; Bull, D. Selective weakening retrofit for existing R.C. structures-Concept, validation and design example. NZSEE 2010, 2, 1320-1331.

4. Basereh, S.; Okumus, P.; Aaleti, S. Reinforced-Concrete Shear Walls Retrofitted Using Weakening and Self-Centering: Numerical Modeling. J. Struct. Eng. 2020, 146, 04020122. [CrossRef]

5. Basereh, S.; Okumus, P.; Aaleti, S. Seismic Retrofit of Reinforced Concrete Shear Walls to Ensure Reparability. Struct. Congr. 2020, 498-509. [CrossRef]

6. Antoniades, K.K.; Salonikios, T.N.; Kappos, A.J. Tests on Seismically Damaged Reinforced Concrete Walls Repaired and Strengthened Using Fiber-Reinforced Polymers. J. Compos. Constr. 2005, 9, 236-246. [CrossRef]

7. Woods, J.E.; Lau, D.T.; Cruz-Noguez, C.A. In-Plane Seismic Strengthening of Nonductile Reinforced Concrete Shear Walls Using Externally Bonded CFRP Sheets. J. Compos. Constr. 2016, 20, 04016052. [CrossRef]

8. Qazi, S.; Michel, L.; Ferrier, E. Seismic behaviour of RC short shear wall strengthened with externally bonded CFRP strips. Compos. Struct. 2019, 211, 390-400. [CrossRef]

9. Di Luccio, G.; Michel, L.; Ferrier, E.; Martinelli, E. Seismic retrofitting of RC walls externally strengthened by flax-FRP strips. Compos. Part B Eng. 2017, 127, 133-149. [CrossRef] 
10. Altin, S.; Kopraman, Y.; Baran, M. Strengthening of RC walls using externally bonding of steel strips. Eng. Struct. 2013, 49, 686-695. [CrossRef]

11. Woods, J.E. Seismic Retrofit of Deficient Reinforced Concrete Shear Walls Using Fibre Reinforced Polymer Sheets Experimental Study and Anchor Design. Master's Thesis, Carleton University, Ottawa, QC, Canada, 2014.

12. Antoniades, K.K.; Salonikios, T.N.; Kappos, A.J. Evaluation of hysteretic response and strength of repaired R/C walls strengthened with FRPs. Eng. Struct. 2007, 29, 2158-2171. [CrossRef]

13. Asplund, B.S. Strengthening Bridge Slabs with Grouted Reinforcement. ACI J. Proc. 1949, 45, 397-406. [CrossRef]

14. Darain, K.M.U.; Jumaat, M.Z.; Shukri, A.A.; Obaydullah, M.; Huda, M.N.; Hosen, M.A.; Hoque, N. Strengthening of RC Beams Using Externally Bonded Reinforcement Combined with Near-Surface Mounted Technique. Polymer 2016, 8, 261. [CrossRef]

15. Abdzaid, H.M.; Kamonna, H.H. Flexural Strengthening of Continuous Reinforced Concrete Beams with Near-Surface-Mounted Reinforcement. Pract. Period. Struct. Des. Constr. 2019, 24, 1-10. [CrossRef]

16. Lim, D.H. An Experimental Study of Flexural Strengthening Method of Reinforced Concrete Beams with Near Surface Mounted CFRP Strips. J. Korean Soc. Civ. Eng. 2013, 33, 131-136. [CrossRef]

17. Sena-Cruz, J.; Barros, J.; Bianco, V.; Bilotta, A.; Bournas, D.; Ceroni, F.; Dalfré, G.; Kotynia, R.; Monti, G.; Nigro, E.; et al. NSM systems. RILEM State Art Rep. 2016, 19, 303-348. [CrossRef]

18. Bianco, V.; Barros, J.A.O.; Monti, G. New approach for modeling the contribution of NSM FRP strips for shear strengthening of RC beams. J. Compos. Constr. 2010, 14, 36-48. [CrossRef]

19. Seo, S.Y.; Lee, M.S.; Feo, L. Flexural analysis of RC beam strengthened by partially de-bonded NSM FRP strip. Compos. Part B Eng. 2016, 101, 21-30. [CrossRef]

20. Sabau, C.; Popescu, C.; Sas, G.; Schmidt, J.W.; Blanksvärd, T.; Täljsten, B. Strengthening of RC beams using bottom and side NSM reinforcement. Compos. Part B Eng. 2018, 149, 82-91. [CrossRef]

21. De Lorenzis, L.; Teng, J.G. Near-surface mounted FRP reinforcement: An emerging technique for strengthening structures. Compos. Part B Eng. 2007, 38, 119-143. [CrossRef]

22. Massone, L.M. Strength prediction of squat structural walls via calibration of a shear-flexure interaction model. Eng. Struct. 2010, 32, 922-932. [CrossRef]

23. Sánchez-Alejandre, A.; Alcocer, S.M. Shear strength of squat reinforced concrete walls subjected to earthquake loading-trends and models. Eng. Struct. 2010, 32, 2466-2476. [CrossRef]

24. Massone, L.M.; Wallace, J.W. Load-Deformation Responses of Slender Reinforced Concrete Walls. ACI Struct. J. 2004, 101, 103-113.

25. Mun, J.-H.; Yang, K.-H. Design Approach for Boundary Element of Flexure-Governed RC Slender Shear Walls Based on Displacement Ductility Ratio. J. Korea Concr. Inst. 2014, 26, 687-694. [CrossRef]

26. Zhang, H.M.; Lu, X.L.; Duan, Y.F.; Zhu, Y. Experimental study on failure mechanism of RC walls with different boundary elements under vertical and lateral loads. Adv. Struct. Eng. 2014, 17, 361-379. [CrossRef]

27. Segura, C.L.; Wallace, J.W. Seismic performance limitations and detailing of slender reinforced concrete walls. ACI Struct. J. 2018, 115, 849-859. [CrossRef]

28. Abdullah, S.A.; Wallace, J.W. Drift Capacity of RC Structural Walls with Special Boundary Elements. ACI Struct. J. 2019, 116. [CrossRef]

29. Abdullah, S.A.; Wallace, J.W. Reliability-Based Design Methodology for Reinforced Concrete Structural Walls with Special Boundary Elements. ACI Struct. J. 2020, 117, 17-29. [CrossRef]

30. Cho, U.; Kim, S.-Y.; Bae, B.-I.; Choi, C.-S. Evaluation of Flexural Performance of Reinforced Concrete Shear Walls According to Flexural Retrofit by Wall End Excavating. J. Archit. Inst. Korea Struct. Constr. 2020, 36, 123-133.

31. Cho, U. Hysteretic Behavior of Existing R/C Rectangular Walls Retrofitted with Boundary Element Detailing. Master's Thesis, Hanyang University, Seoul, Korea, 2020.

32. Qian, J.; Jiang, Z.; Ji, X. Behavior of steel tube-reinforced concrete composite walls subjected to high axial force and cyclic loading. Eng. Struct. 2012, 36, 173-184. [CrossRef]

33. Ren, F.; Chen, J.; Chen, G.; Guo, Y.; Jiang, T. Seismic behavior of composite shear walls incorporating concrete-filled steel and FRP tubes as boundary elements. Eng. Struct. 2018, 168, 405-419. [CrossRef]

34. Wu, L.; Tian, Y.; Su, Y.; Chen, H. Seismic performance of precast composite shear walls reinforced by concrete-filled steel tubes. Eng. Struct. 2018, 162, 72-83. [CrossRef]

35. HILTI. Rebar for Engineers Part I: Application Basics and Design by Principles of Reinforcing According to ACI 318; HILTI: Schaan, Liechtenstein, 2019.

36. HILTI. Rebar for Engineers Part II: Hit Rebar Design Based on ACI 318 and Fire, Corrosion; HILTI: Schaan, Liechtenstein, 2019.

37. AIK. Korean Building Code and Commentary (KBC 2016); Architectural Institute of Korea: Seoul, Korea, 2016.

38. ACI. Building Code Requirements for Structural Concrete (ACI 318-19); American Concrete Institute: Farmington Hills, MI, USA, 2019.

39. ICC-ES. Hilti Hit-Hy 200 Adhesive Anchors and Post Installed Reinforcing Bar Connections in Concrete (ESR-3187); ICC Evauation Service: Whittier, CA, USA, 2018.

40. Attard, M.M.; Setunge, S. Stress-strain relationship of confined and unconfined concrete. ACI Mater. J. 1996, 93, 432-442. [CrossRef]

41. KSA. Steel Bars for Concrete Reinforcement (KS D 3504); Korean Standards Association: Seoul, Korea, 2019. (In Korean) 
42. ACI. Acceptance Criteria for Special Unbonded Post-Tensioned Precast Structural Walls Based on Validation Testing (ACI ITG-5.1-07); American Concrete Institute: Detroit, MI, USA, 2007.

43. Kurama, Y.C. Seismic Design of Partially Post-Tensioned Precast Concrete Walls. PCI J. 2005, 50, 100-125. [CrossRef]

44. Smith, B.J.; Kurama, Y.C.; Mcginnis, M.J. Hybrid Precast Wall Systems for Seismic Regions; Department of Civil Engineering and Geological Sciences, University of Notre Dame: Notre Dame, IN, USA, 2012; p. 137.

45. Priestley, M.J.N.; Evison, R.J.; Carr, A.J. Seismic Response of Structures Free To Rock on Their Foundations. Bull. New Zeal. Natl. Soc. Earthq. Eng. 1978, 11, 141-150. 